\title{
Phenolic Compounds from Psidium guajava (Linn.) Leaves: Effect of the Extraction-Assisted Method Upon Total Phenolics Content and Antioxidant Activity
}

\author{
Venâncio Alves Amaral ${ }^{1}{ }^{(\mathbb{D}}$, Thais Francine Ribeiro Alves ${ }^{1}{ }^{(\mathbb{D})}$, Juliana Ferreira de Souza ${ }^{1}$, \\ Fernando Batain ${ }^{1}$ (D), Kessi Marie de Moura Crescencio ${ }^{1}$ (D), Victória Soares Soeiro ${ }^{1}$ (D), \\ Cecília Torqueti de Barros ${ }^{1(D)}$, Marco Vinícius Chaud 1*(D) \\ 1 Laboratory of Biomaterials and Nanotechnology, University of Sorocaba - UNISO, University City Campus, Raposo \\ Tavares, Vila Artura, ZC: 18023-000, Sorocaba, São Paulo, Brazil \\ * Correspondence: marco.chaud@prof.uniso.br;
}

Scopus Author ID 8845188500

Received: 15.08.2020; Revised: 8.09.2020; Accepted: 9.09.2020; Published: 11.09.2020

\begin{abstract}
The aim of this study was to investigate the influence of the extraction method on the dry extract yield of guava leaves, correlating the total phenolic content (TPC) with the antioxidant activity. The dry extracts were obtained from hydroethanolic (50 and 70\%) extract using the ultrasound-assisted method. Folin-Ciocalteau reagent was used to determine the content of TPC. DPPH (2,2-diphenyl-1-picrylhydrazyl) in vitro assay was used to determine the ability to scavenge free radicals. The results analyses demonstrated that the ultrasound-assisted method produced a higher yield in both dry extracts (11\%), in contrast to the conventional method. The 50\% hydroethanolic solvent was more efficient in the extraction of bioactive compounds. Both extracts showed a positive correlation of phenolic content with antioxidant activity. The FTIR spectrograms showed changes in the chemical groups, as well as determining the aromaticity index of the extracts, indicating a higher aromatic prevalence to the solvent 50\%, although it presented simpler phenolic structures. In conclusion, the results provide an important basis for the use of phenolic compounds extracted from guava leaves, not only due to the antioxidant activity exerted, however, for potential use as a crosslinking agent of sulfated and non-sulfated glycosaminoglycan (GAG).
\end{abstract}

Keywords: Psidium guajava Linn.; hydroethanolic solvent; ultrasound-assisted; phenolic compounds; antioxidant activity; aromaticity index.

(C) 2020 by the authors. This article is an open-access article distributed under the terms and conditions of the Creative Commons Attribution (CC BY) license (https://creativecommons.org/licenses/by/4.0/).

\section{Introduction}

Psidium guajava (guava) is a plant that can reach 8 to 10 meters in height; it belongs to the phylum Magnoliophyta, class Magnoliopsida, and family Myrtaceae. The guava is found in many tropical and subtropical regions [1,2].

Different parts of this plant are widely used worldwide, either as food or in traditional medicine [3]. Given its use in health practices, in vitro and in vivo pharmacological research has been widely used to demonstrate the potential effect of guava leaf extracts in helping to treat a variety of highly prevalent diseases, investigating the use of extracts by traditional medicine in cases such as diabetes mellitus, cardiovascular diseases, cancer, diarrhea, bacterial infection, and antiparasitic [4,5]. The biological activities of guava extracts have been attributed to secondary metabolic compounds, mainly to phenolic compounds [6].

Phenolic compounds represent a wide variety of substances distributed in the plant kingdom and are the most abundant secondary metabolites of plants, with more than 8000 phenolic structures already detected, from simple molecules, such as phenolic acids, to highly https://biointerfaceresearch.com/ 
polymerized substances, such as tannins [7]. The chemical structure of phenolic compounds is characterized by the presence of one or more aromatic rings attached to at least one hydroxyl radical and/or other functional substitutes, and can also be divided according to the number of phenolic rings and the structures to which they are attached linked; these characteristics confer antioxidant properties to these compounds [8].

Antioxidants are defined as molecules that can slow, inhibit, or prevent the oxidation process, eliminating free radicals and decreasing oxidative stress [9]. Oxidative stress is characterized as an imbalance in which excessive amounts of reactive oxygen and/or nitrogen species (ROS/RNS), such as hydroxyl radical $(\cdot \mathrm{OH})$, superoxide anion $\left(\mathrm{O}^{2-}\right)$, hydrogen peroxide $\left(\mathrm{H}_{2} \mathrm{O}_{2}\right)$, and peroxy-nitrite $\left(\mathrm{ONOO}^{-}\right)$exceeds the endogenous capacity, resulting in the oxidation of a variety of biomacromolecules [10,11].

The antioxidant properties of phenolic compounds can be mediated by three mechanisms: (I) eliminate radical species such as ROS/RNS; (II) suppress the formation of ROS/RNS by inhibiting some enzymes or chelating trace metals involved in the production of free radicals; and (III) regulate or protect the antioxidant defense $[12,10]$.

In addition to the antioxidant activity expressed by phenolic compounds, due to their high compatibility with free radicals, these compounds have potential use in the chemical crosslinking process due to their structure composed of hydroxyl groups and other functional groups, such as carboxyl and sulfated groups, being able to effectively perform intermolecular interactions with proteins and glycosaminoglycans [13], like collagen, hyaluronan, chondroitin sulfate, and ulvan.

Chemical crosslinking is a highly versatile method with good mechanical stability for the manufacture of hydrogels [14], films [15], and scaffolds [16]. Sodium periodate and aldehyde compounds are generally used for this purpose, such as glutaraldehyde and formaldehyde. Although they are very good crosslinking agents, they are not preferable due to their physiological toxicity [17]. Therefore, the search for biocompatible natural compounds has been indicated as an important alternative for use as crosslinking agents.

Phenolic compounds have been extracted using conventional methods, such as maceration, infusion, percolation, countercurrent extraction, and Soxhlet. However, these methods have some disadvantages, such as long extraction times, requiring relatively large amounts of plant samples, possible degradation or transformation of bioactive compounds, and higher consumption of organic solvent $[18,19]$.

In a study carried out by Seo et al. (2014) [11], hydroethanolic extracts (50 and 70\%) were prepared with guava leaves by the maceration method. To obtain the extract, $100 \mathrm{~g}$ of leaves were used in $1.5 \mathrm{~L}$ of solvent for 4 days at room temperature. The results of this study confirmed the contents of TPC of $185 \mathrm{mg} \mathrm{GAE} / \mathrm{g}$ and $150 \mathrm{mg}$ GAE/g for hydroethanolic extracts 50 and $70 \%$, respectively.

In contrast to conventional methods, ultrasound-assisted extraction has been widely requested for applications in the food and pharmaceutical industries, as it presents advantages combined with greater productivity, yield, and selectivity of the compounds of interest [20].

Given the importance of the antioxidant activity exerted by the phenolic compounds present in guava leaves and their potential use as a crosslinking agent, this study aimed to investigate the effects of the ultrasound-assisted method to optimize the extraction of TPC from hydroethanolic extracts. In addition, correlate the TPC with the ability to eliminate free radicals in vitro. We hypothesized that TPC is capable of crosslinking glycosaminoglycans after the partial reaction between $\mathrm{GAG}$ and sodium periodate $\left(\mathrm{NaIO}_{4}\right)$. 


\section{Materials and Methods}

\subsection{Materials.}

The leaves of the guava plant (Psidium guajava Linn. var. Pomifera) from the seedling bed was kindly donated by the Division of Parks and Conservation Units of the Secretariat for the Environment (Sorocaba, São Paulo, Brazil), ethanol (Synth, São Paulo, Brazil), hydrochloric acid (Neon, São Paulo, Brazil). Folin-Ciocalteau reagent (Dinâmica, São Paulo, Brazil), sodium carbonate (Dinâmica, São Paulo, Brazil), gallic acid (Dinâmica, São Paulo, Brazil). 2,2-diphenyl-1-picrylhydrazyl (Sigma-Aldrich, Steinheim, Germany), methanol (Chemco, São Paulo, Brazil). All reagents used were analytical grade.

\subsection{Obtaining plant material.}

The guava leaves were harvested by hand, carefully packed for transport, and on the same day, the leaves were handled to remove debris and washed to remove impurities. The leaves were rinsed with 70\% ethanol to reduce drying time and kept in an oven with forced air circulation (Tecnal, TE-394, São Paulo, Brazil) at $37{ }^{\circ} \mathrm{C}$ to constant weight. The dried leaves were ground, and the powder was standardized using a standard sieve (20 mesh, $0.833 \mathrm{~mm}$ ), and stored in an airtight container until the studies were carried out.

\subsection{Extraction of total phenolic content.}

The ultrasound-assisted extraction was carried out using as solvent hydroethanolic 50\% and $70 \% \mathrm{v} / \mathrm{v}$, acidified with hydrochloric acid $(0.5 \% \mathrm{v} / \mathrm{v})$, and application of ultrasonic wave single frequency $(40 \mathrm{kHz}$ ). For the extraction, $10 \mathrm{~g}$ of standardized guava leaf powder (SGLP) was placed in Erlenmeyer and dispersed in $150 \mathrm{ml}$ of previously acidified ethanol $50 \% \mathrm{v} / \mathrm{v}$ and kept in an ultrasound bath (Unique, USC-3300, São Paulo, Brazil) for $60 \mathrm{~min}$., at $30{ }^{\circ} \mathrm{C}$. The same process was carried out using ethanol $70 \% \mathrm{v} / \mathrm{v}$ previously acidified. Both dispersions were vacuum filtered (Whatman ${ }^{\circledR}$ cotton filter, grade 44: $3 \mu \mathrm{m}$ ) and stored away from light and heat. The residue retained in the cotton filter was reprocessed using the same extraction conditions already described. The extracts from the first and second extraction processes were mixes.

The solvent was eliminated using a rotatory evaporator (Tecnal, TE-211, São Paulo, Brazil). The concentrated extract was resuspended in ultrapure water and dried by lyophilization (Liofilizador - L101, Liotop, São Paulo, Brazil). The dry extract of guava leaves from acidified ethanol 50\% (DEGL-50) e ethanol 70\% (DEGL-70) were stored away from humidity, light, and heat.

The mass yield of the dry extracts was calculated according to Eq. (1).

$$
\text { Dry extract yield }(\%)=\frac{\text { Dry extracts }(g)}{\text { Powder guava leaves }(g)} \times 100
$$

\subsection{Determination of total soluble phenolic compounds.}

The total soluble phenolic content from DEGL-50 and DEGL-70 samples were determined using the Folin-Ciocalteau colorimetric method described by Çam and İçyer (2015) [21] with modifications. The dry extract was solubilized in ultrapure water at a concentration of $1 \mathrm{mg} / \mathrm{mL}$. This solution was filtered through a cotton filter, discarding the first $25 \mathrm{~mL}$. The 
filtrate as the standard solution (SS $-0.001 \mathrm{~g} / \mathrm{mL}$ ). After that, an aliquot of $50 \mu \mathrm{L}$ the standard solution was collected and transferred to a test tube with $2.5 \mathrm{~mL}$ of the Folin-Ciocalteau reagent being added. The mixture was slightly stirred, and $2 \mathrm{~mL}$ of a solution of anhydrous sodium carbonate $\left(\mathrm{Na}_{2} \mathrm{CO}_{3}\right)$ at $7.5 \%(\mathrm{w} / \mathrm{v})$ was added. The mixture was incubated for 15 minutes in a thermostatic bath (Brookfield, TC 550, Middleborough, USA) at $50{ }^{\circ} \mathrm{C}$ and finally cooled in a freezer at $-18{ }^{\circ} \mathrm{C}$ for $5 \mathrm{~min}$.

The samples were analyzed in triplicate, and the TPC was determined at a wavelength of $760 \mathrm{~nm}$ in a UV/Vis-spectrophotometer (Femto 800XI, São Paulo, Brazil), using FemtoScan Software. For greater reliability of the assay, a white reagent (ultrapure water) was conducted under the same conditions.

For the quantification of TPC, the research group previously constructed an analytical curve with concentration points between $50-400 \mu \mathrm{g} / \mathrm{mL}$ of gallic acid, and the results were expressed in $\mathrm{mg} / \mathrm{g}$ gallic acid equivalent (GAE) of the samples [22].

\subsection{In vitro antioxidant activity.}

The antioxidant activity of the TPC in the DEGL-50 and DEGL-70 samples were determined using a solution $50 \mu \mathrm{L}$ of each dry extract $(1 \mathrm{mg} / \mathrm{mL})$ and mixed with $2 \mathrm{~mL}$ of 100 $\mu \mathrm{M} \mathrm{DPPH} \mathrm{(4} \mathrm{mg/100} \mathrm{mL} \mathrm{methanol)} \mathrm{as} \mathrm{free} \mathrm{radical.} \mathrm{The} \mathrm{mixture} \mathrm{was} \mathrm{placed} \mathrm{in} \mathrm{the} \mathrm{dark} \mathrm{at} \mathrm{room}$ temperature for 60 minutes. After that, the absorbance of the samples was analyzed in triplicate at $520 \mathrm{~nm}$ by UV/Vis-spectrophotometer, using purified water for zero adjustments [23].

Assessment of the scavenging abilities phenolic content on DPPH expressed as percent inhibition was calculated according to Eq. (2).

DPPH scavenging effect $(\%)=\frac{A b s 1-A b s 2}{A b s 1} \times 100$

Where Abs1 represents the absorbance of the control at 60 minutes, and Abs2 is the absorbance of the sample at 60 minutes.

\subsection{Fourier transform infrared spectroscopy (FTIR).}

The FTIR analysis (Shimadzu, IRAffinity-1, Kyoto, Japan) was used to collect FTIR spectra via LabSolutions Software v.2.10. The $\mathrm{KBr}$ discs were prepared using a hydrostatic press, with a mass of $2 \mathrm{mg}$ of sample (dry extract) mixed with $300 \mathrm{mg}$ of $\mathrm{KBr}$. The FTIR spectra were collected between $4000-400 \mathrm{~cm}^{-1}$, with a resolution of $4 \mathrm{~cm}^{-1}$ and 32 scans.

\subsection{Determination of the aromaticity index by FTIR.}

The aromaticity index provides an estimate of the aromatic character of the analyzed samples, through the ratio between the peak absorption intensity around $1620 \mathrm{~cm}^{-1}$, attributed to the aromatic groups, with the peak absorption $\mathrm{n}$ intensity around $2920 \mathrm{~cm}^{-1}$, which represents aliphatic groups [24,25]. The absorption intensity values were obtained using FTIR spectra and measured using Labsolutions Software v.2.10. The sample's aromaticity index was calculated according to Eq. (3).

$$
\text { Aromaticity index }(A I)=\frac{I 1620}{I 2920}
$$


Where I-1620 represents the absorption intensity in the wavenumber around $1620 \mathrm{~cm}^{-1}$ and I2920 is the absorption intensity in the wavenumber around $2920 \mathrm{~cm}^{-1}$.

\section{Results and Discussion}

\subsection{Efficiency of ultrasound-assisted extraction method.}

For the extraction of TPC from leaves of different species of plant, the most used solvents are the water and the organic solvents such as ethanol, methanol chloroform, hexane, ethyl acetate, and acetone. Because of the diversity of available solvents, the choice of the most suitable solvent has become a crucial factor, both to increase the yield in TPC, to improve biological safety, and environmentally friendly [6].

The yield of the ultrasound-assisted extraction (UAE) method measured by the dry extract weight after freeze-drying was $11.4 \%$ for DEGL-50 and for DEGL-70 and $11.7 \%$ for DEGL-70\%.

Dry extracts obtained by the maceration method in ethanol 50\% [26] and ethanol 70\% [27] were respectively $1.66 \%$ (three days of maceration) and $2.75 \%$ (four days of maceration). Unlike the methods of extraction by maceration where the time and dielectric constant ( $\mathrm{Er}$ ) of ethanol 50\% ( $\mathrm{Er} \sim 52)$ and $70 \%(\mathrm{Er} \sim 40)$, at a temperature of $25{ }^{\circ} \mathrm{C}$, influenced the process yield, the UAE method for $60 \mathrm{~min}$ at $30{ }^{\circ} \mathrm{C}$, a frequency of $40 \mathrm{kHz}$ have not affected by the solvent $\mathrm{Er}$. The powerfulness of the UAE method compared to maceration, can be explained by the effect of ultrasonic energy through a solvent system containing solid particles. So, the energy in the form of waves generates a perpendicular or parallel force on the liquid surface, that converts the sonic energy into mechanical energy, equivalent to several thousand of atmospheric pressures, which is responsible for breaking the cell wall and dissolving phenolic compounds and another soluble in a specific solvent.

\subsection{Determination of total phenolic compounds.}

The analytical curve was developed to determine TPC (Figure 1). The determination coefficient, designated $\mathrm{R}^{2}$, was observed in the concentration range of $50-400 \mu \mathrm{g} / \mathrm{mL}$. The data from the linear regression analysis for the calibration graph showed a good coefficient of determination was 0.998 , and the linear regression equation was $\mathrm{y}=0.0017 \mathrm{x}-0.0832$ (22). In these conditions, the analytical validation method by UV/Vis-spectrophotometry to determine the polyphenol content proved that the method was linear, reliable, robust, reproducible, easy to perform, and low cost. This methodology complies with the requirements for analytical application and to guarantee the reliability of the results $[28,29]$.

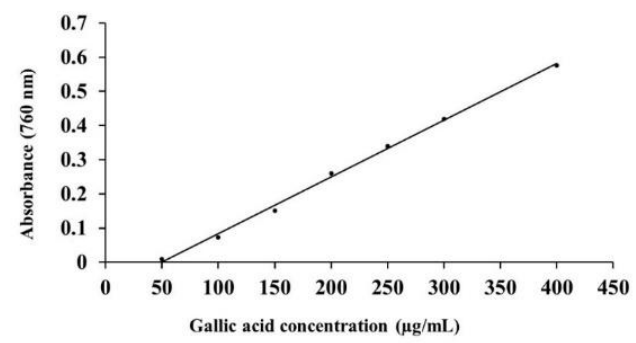

Figure 1. Analytical curve to determine total phenols content in the dry extract of guava leaf from ethanol $50 \%$ (DEGL-50) and ethanol 70\% (DEGL-70) samples.

The TPC is the dry extract estimated spectrophotometrically by the Folin-Ciocalteu reaction [30-32]. The Folin-Ciocalteau reagent (FCR) consists of a mixture of 
phosphomolybdate and phosphotungstate, whose basic principles are a redox reaction with the phenolic compounds available in the sample to form a blue-colored complex that absorbs radiation and allows it to be quantified by visible light spectrophotometry $[33,34]$.

The FCR works by measuring the amount of analyte needed to inhibit oxidation of the reactive. However, the reaction occurs with other reducing substances that contain, for example, nitrogen such as guanidine and hydroxylamine, carotenoids, amino acids, sugars, and ascorbates. Faced with all the limitations, FCR is the adequate way to use the term FolinCiocalteau index, and it had been considered in the present study to estimate the TPC expressed in mg gallic acid.

In this study, the solvent, the time, and temperature of the extraction process have designed to decrease the presence of reactive organic acids in the extracts. Although the highest content of TPC has found in DEGL-50, Folin-Ciocalteau index of 0.57 (574.4 mg GAE/g), while the DEGL-70 sample had a Folin-Ciocalteau index of 0.42 (426 mg GAE/g) in relation to the dry extracts, it is needed consider that due to the highest water solubility of organic acids its content in DEGL-50 extract may be more than in DELG-70 extract. The study carried out by Seo et al. (2014) [11] TPC content of $185 \mathrm{mg} \mathrm{GAE} / \mathrm{g}$ and $150 \mathrm{mg}$ GAE/g in extracts prepared by maceration method with ethanol $50 \%$ and $70 \%$, respectively. Other reports in the literature confirmed levels of $288.56 \mathrm{mg} \mathrm{GAE} / \mathrm{g}$ on the dry extract obtained with ethanol $50 \%$ [26], and on the dry extract obtained with $70 \%$, the TPC of $229.80 \mathrm{mg} \mathrm{GAE} / \mathrm{g}$ were recorded [35].

\subsection{In vitro antioxidant activity.}

The formation of free radicals by the body under normal circumstances is inevitable, given that these compounds regulate cell growth, in addition to inhibiting the proliferation of viruses and bacteria [36]. Oxidative stress can damage the body's cells, leading to a range of disease due to free radical that affect, for example, the central nervous system, accelerates the onset of cardiovascular disease, age-related vision decline, disorders autoimmune, inflammatory and cutaneous, degenerative genetic disease. Camarena-Tello et al. (2018) [6] report that the consumption of antioxidants significantly decreases the adverse effects caused by the excess of some reactive oxygen and nitrogen species in the human body.

DPPH ( $\alpha, \alpha$-diphenyl- $\beta$-picrylhydrazyl) method has been widely applied to estimate antioxidant activity due to free radical scavenging and because it may be utilized in aqueous and nonpolar organic solvents. Besides, it can be used to examine both lipophilic and hydrophilic antioxidants; it is rapid, inexpensive, and simple.

Amongst all the available methods, the DPPH method offers the first approach for evaluating the overall antioxidant potential of an extract or other biological sources [37,38].

On mixing DPPH solution with a substance that can donate a hydrogen atom, it gives rise to the reduced form with the loss of violet color with absorption in ethanol solution at around $520 \mathrm{~nm}[23,39]$.

According to Morais-Braga et al. (2017) [27], the main phenolic compounds detected in guava leaf extracts are gallic acid, catechin, chlorogenic acid, caffeic acid, epicatechin, rutin, quercetin, kaempferol, and luteolin. These compounds play an important role in antioxidant activity, not only because of their ability to donate hydrogen or electrons but also because of their stable intermediate radicals, preventing the oxidation [40].

Based on the data obtained from this study, both the extracts were effective free radical inhibitor or scavenger, as well as a primary antioxidant that reacts with free radicals, which 
may limit free radical damage occurring in the human body. The analysis of results by DPPH method showed that the greatest free radical scavenging was estimated for the DEGL-50 (70 $\%)$, while the DEGL-70 sample (63\%). This result shows that the extraction process used reached the greatest performance to isolate phenolics compounds, the same when compared to another extraction method reported in the literature, including the ultrasound-assisted extraction.

\subsection{Fourier transform infrared spectroscopy (FTIR).}

The FTIR spectrum of guava leaves and DEGL-50 and DEGL-70 samples were obtained using medium infrared $\left(4000-400 \mathrm{~cm}^{-1}\right)$ and are shown in Figure 2 and Table 1 . The presence of characteristic peaks was observed in the region of the functional groups (4000 $\left.1300 \mathrm{~cm}^{-1}\right)$, digital printing region $\left(1300-900 \mathrm{~cm}^{-1}\right)$, and in the final region $\left(900-400 \mathrm{~cm}^{-1}\right)$ of the spectra [41].

In the DEGL-70 spectrum, characteristic peaks were observed at $3383 \mathrm{~cm}^{-1}$ attributed to the hydroxyl stretch $(\mathrm{OH})$ vibration; in the regions at $2927 \mathrm{~cm}^{-1}$ and $2856 \mathrm{~cm}^{-1}$, they are attributed respectively to asymmetric and symmetric vibration of aliphatic stretching structures. In $1693 \mathrm{~cm}^{-1}$ corresponds to the elongation of the carbonyl group $(\mathrm{C}=\mathrm{O})$, and in the $1614 \mathrm{~cm}^{-1}, 1517 \mathrm{~cm}^{-1}$ regions are assigned respectively to the $\mathrm{CH}$ group and $\mathrm{C}=\mathrm{C}$ elongation bands, typical of aromatic molecules.

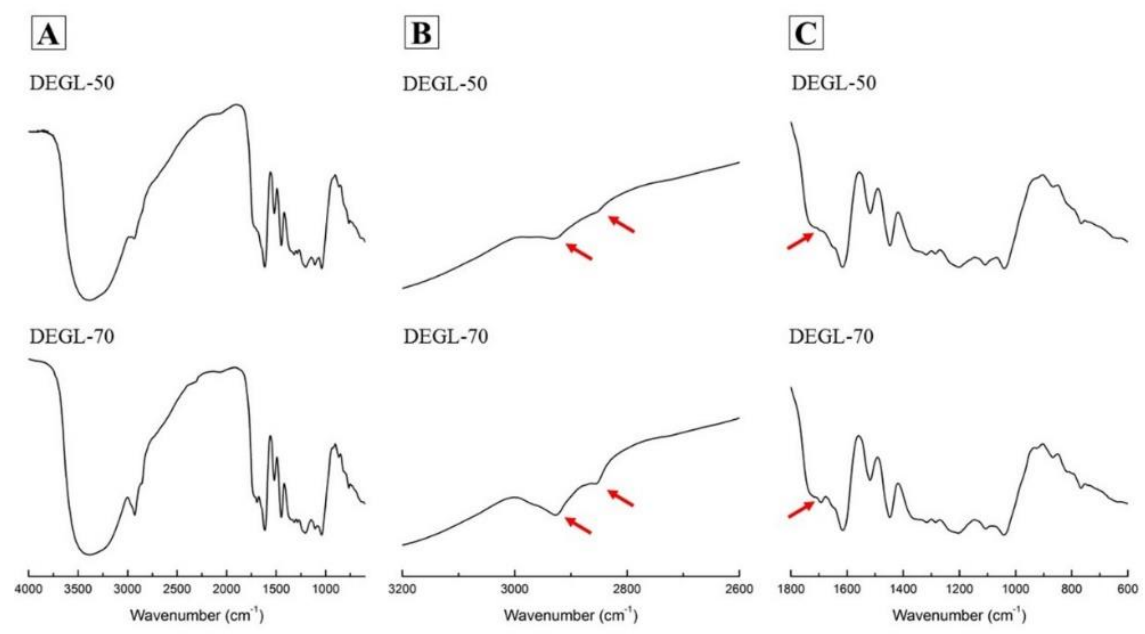

Figure 2. FTIR spectra of dry extract of guava leaves from ethanol 50\% (DEGL-50) and ethanol 70\% (DEGL-

70) samples. The arrows on panel $B$ and $C$ indicate changes between the spectra of the samples.

The transmittance at $1446 \mathrm{~cm}^{-1}$ corresponds to the antisymmetric flexion in the $\mathrm{CH}_{3}$ plane. The regions at $1203 \mathrm{~cm}^{-1}, 1107 \mathrm{~cm}^{-1}$ and $1041 \mathrm{~cm}^{-1}$ correspond to $\mathrm{C}-\mathrm{O}$ stretching vibrations. Finally, the $767 \mathrm{~cm}^{-1}$ regions is attributed to out-of-plane conformations in $\mathrm{CH}$ [4244].

The structural chemical conformation of the DEGL-50 and DEGL-70 samples recorded by the FTIR spectrum showed similar peaks. However, peak shifts and changes in transmittance intensity have been observed. In the DEGL-50 sample, in addition to the peak displacements, there were significant reductions in peak transmittance intensity in the regions of $2929 \mathrm{~cm}^{-1}, 2856 \mathrm{~cm}^{-1}$, and $1693 \mathrm{~cm}^{-1}$ (highlighted with arrows in Figure 2-B and C). The positions and assignments of the detailed peaks are listed in Table 1. 
Table 1. Wavenumber assignments of FTIR spectra of dry extract of guava leaves from ethanol 50\% (DEGL50) and ethanol 70\% (DEGL-70) samples.

\begin{tabular}{|c|c|c|}
\hline \multicolumn{2}{|c|}{ Samples } & Attribution \\
\hline DEGL-50 & DEGL-70 & \\
\hline \multicolumn{2}{|c|}{ Peak $\left(\mathrm{cm}^{-1}\right)$} & \\
\hline 3383 & 3383 & $\mathrm{OH}$, stretch vibration \\
\hline 2931 & 2927 & $\mathrm{CH}$, asymmetric stretching vibration of aliphatic \\
\hline- & 2856 & $\mathrm{CH}$, symmetric stretching vibration of aliphatic \\
\hline- & 1693 & $\mathrm{C}=\mathrm{O}$, stretching band of carbonyl \\
\hline 1616 & 1614 & Aromatic $\mathrm{CH}$ bonds \\
\hline 1517 & 1517 & $\mathrm{C}=\mathrm{C}$, stretching bands \\
\hline 1446 & 1446 & Antisymmetric in-plane bending of $\mathrm{CH}_{3}$ \\
\hline 1201 & 1203 & Stretching vibration of $\mathrm{C}-\mathrm{O}$ \\
\hline 1109 & 1107 & Stretching vibration of $\mathrm{C}-\mathrm{O}$ \\
\hline 1039 & 1041 & Stretching vibration of $\mathrm{C}-\mathrm{O}$ \\
\hline 765 & 767 & $\mathrm{CH}$ out-of-plane conformations \\
\hline
\end{tabular}

Through the data recorded by the FTIR, it was possible to verify changes in the spectra of the samples DEGL-50 and DEGL-70, confirming that the proportion of the solvent used in the extraction process influences the diversity of bioactive compounds extracted from guava leaves. The ethanol solvent, when used to extract bioactive substances, favors the extraction of compounds of intermediate polarity due to its reduced dielectric constant $\left(\mathrm{Er} \sim 24.30\right.$ at $\left.25^{\circ} \mathrm{C}\right)$ when compared to water $\left(\mathrm{Er} \sim 78.36\right.$ at $\left.25{ }^{\circ} \mathrm{C}\right)$ [45]. The hydroethanolic solvents used in the study promote changes in the $\mathrm{Er}$, resulting in $\sim 52$ and $\sim 40$ for the percentages of 50 and $70 \%$, respectively. Both the extractive capacity of phenolic compounds and the expression of antioxidant activity showed a direct correlation with this property. In addition, the observed changes in the spectra (Figure 2-B and $\mathrm{C}$ ) attributed to the reductions in the asymmetric and symmetric vibration of the $\mathrm{CH}$ stretch of the aliphatic group and the $\mathrm{C}=\mathrm{O}$ carbonyl elongation band, indicating the extraction of compounds with simpler structures for the DEGL-50 extract.

\subsection{Determination of the aromaticity index by FTIR.}

The FTIR technique provides reliable information for identifying the structure of chemical functional groups in complex mixtures, including quantification by absorbance or transmittance of the analyzed compounds $[41,46]$.

The values of the aromaticity index (I1620/I2920) were calculated from the absorbance data presented in the FTIR spectra, obtaining values of 1.432 and 1.225, for samples DEGL50 and DEGL-70, respectively (Table 2).

The aromatic index equation is a useful method for determining total phenolic compounds. Then, the total phenolics content was determined based on the aromatic index before used to evaluate the presence of aromatic groups in humic compounds [24] and to estimate aromatic properties in pedogenic and geological organics material [25] to estimate the aromatic characteristics present in humic substances of compounds and in the study presented by Dick et al. (2006) [25]

Table 2. Aromaticity index of dry extract of guava leaves from ethanol 50\% (DEGL-50) and ethanol 70\% (DEGL-70) samples.

\begin{tabular}{c|c|c|c|c|c}
\multirow{2}{*}{ Samples } & $\begin{array}{c}\text { Aromatic* and aliphatic } \\
\text { groups }\left(\mathrm{cm}^{-1}\right)\end{array}$ & $\begin{array}{c}\text { Base H } \\
\left(\mathrm{cm}^{-1}\right)\end{array}$ & $\begin{array}{c}\text { Base L } \\
\left(\mathrm{cm}^{-1}\right)\end{array}$ & $\begin{array}{c}\text { Absorption } \\
\text { intensity }\end{array}$ & $\begin{array}{c}\text { Aromaticity index } \\
(\mathrm{AI})\end{array}$ \\
\hline \multirow{2}{*}{ DEGL-50 } & $1616^{*}$ & 1849 & 1556 & 0.596 & \multirow{2}{*}{1.432} \\
\cline { 2 - 4 } & $2931^{\#}$ & 2958 & 1921 & 0.416 & \\
\hline \multirow{2}{*}{ DEGL-70 } & $1614^{*}$ & 1676 & 1558 & 0.673 & \multirow{2}{*}{1.225}
\end{tabular}


The correlation between the values of total phenolic compounds determined by gallic acid equivalence (GAE) and the aromaticity index determined by FTIR, showed a high correlation, reaffirming that the sample DEGL-50 has the highest phenolic contents.

\subsection{Hypothesis for the crosslinking reaction of glycosaminoglycan by "click chemistry".}

Figure 3 shows the oxidative cleavage of the glycosidic group of sulfated glycosaminoglycan (ulvan), and crosslinking of the phenolic group.

A

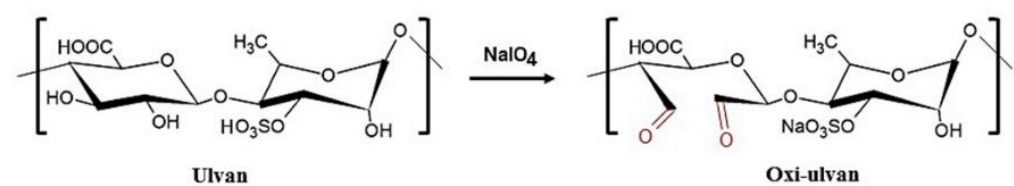

B

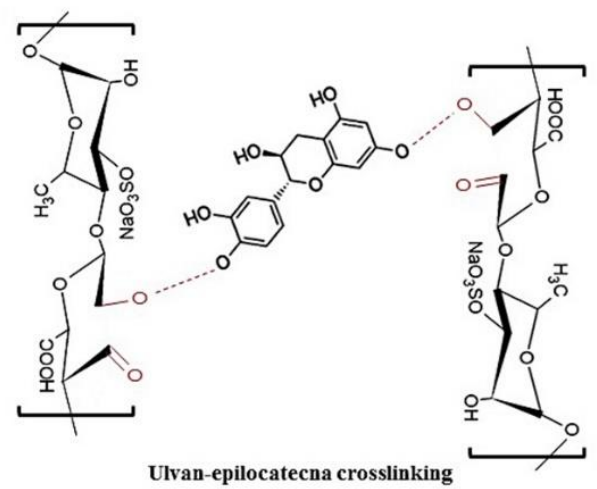

Figure 3. The hypothesis of glycosaminoglycans crosslinking by. A - Cleavage of the glycosidic group of the ulvan glucuronic acids; B - "click" reaction of epilocatecna for crosslinking of ulvan molecules.

\section{Conclusions}

The choice of the extraction method and experimental variables to obtain the dry extracts of the leaves of Psidium guajava Linn (var. Pomifera) were the most important factors to guarantee a higher yield. The ultrasound-assisted extraction technique, whose main effect in improving the process, is attributed to the acoustic cavitations produced in the solvent through the passage of an ultrasonic wave. These cavitations create shear stresses, causing the cell walls to rupture and allowing greater penetration of the solvent into the material matrix. Both hydroethanolic solvents showed a potential capable of obtaining dry extracts in $11 \%$ mass. The effect of the solvent dielectric constant had a direct influence on the content of total phenolic compounds, presenting a higher content for the DEGL-50 sample. The phenolic compounds present in both samples showed the ability to donate electrons and hydrogen atoms, with antioxidant activity of $70 \%$ and $63 \%$ (DEGL-50 > DEGL-70). The FTIR identified the main characteristic peaks of the samples, providing significant data on the chemical structure, determining the aromaticity index; this data set confirmed that the use of a hydroethanolic solvent $(50 \%)$ increases the prevalence of aromatic structures in the extract; however, the extraction results in phenolic compounds with simpler structures. In conclusion, the results above provide a potential basis for the use of phenolic compounds extracted from guava leaves as crosslinking agents glycosaminoglycans (hyaluronic acid, chondroitin sulfate, ulvan) and proteins (collagen).

\section{Funding}

This research received no external funding. 


\section{Acknowledgments}

This work was supported by the National Council for Scientific and Technological-Brazil (CNPq grant number: 425271/2016-1), the São Paulo Research Foundation (FAPESP grant numbers: 2011/21219-5; 2018/13432-0), and the University of Sorocaba (UNISO), São Paulo, Brazil.

\section{Conflicts of Interest}

The authors declare no conflict of interest.

\section{References}

1. Shruthi, S.D.; Roshan, A.; Timilsina, S.S.; Sunita, S. A review on the medical plant Psidium guajava Linn. (Myrtaceae). J Drug Deliv Ther 2013, 3, 162-168, https://doi.org/10.22270/jddt.v3i2.404.

2. Ocheje, J. Toxicological Studies On The Aqueous Leaf Extract Of Psidium guajava In Albino Rats. Salem Univ J Life Sci. 2019, 1, 70-76.

3. Daswani, P.G.; Gholkar, M.S.; Birdi, T.J.J.P.r. Psidium guajava: A single plant for multiple health problems of rural Indian population. 2017, 11, 167-74, https://dx.doi.org/10.4103/phrev.phrev_17_17.

4. Díaz-de-Cerio, E.; Verardo, V.; Gómez-Caravaca, A.M.; Fernández-Gutiérrez, A.; Segura-Carretero, A. Health Effects of Psidium guajava L. Leaves: An Overview of the Last Decade. International Journal of Molecular Sciences 2017, 18, 1-31. https://doi.org/10.3390/ijms18040897.

5. Madubuonu, N.; Aisida, S.O.; Ahmad, I.; Botha, S.; Zhao, T.-k.; Maaza, M.; Ezema, F.I. Bio-inspired iron oxide nanoparticles using Psidium guajava aqueous extract for antibacterial activity. Applied Physics A 2020, 126, 1-8, https://doi.org/10.1007/s00339-019-3249-6.

6. Camarena-Tello, J.C.; Martínez-Flores, H.E.; Garnica-Romo, M.G.; Padilla-Ramírez, J.S.; SaavedraMolina, A.; Alvarez-Cortes, O.; Bartolomé-Camacho, M.C.; Rodiles-López, J.O. Quantification of Phenolic Compounds and In Vitro Radical Scavenging Abilities with Leaf Extracts from Two Varieties of Psidium guajava L. Antioxidants 2018, 7, 1-12, https://doi.org/10.3390/antiox7030034.

7. Elnour, A.; Mirghani, M.; Musa, K.; Kabbashi, N.; Alam, M.J.H.S.J. Challenges of extraction techniques of natural antioxidants and their potential application opportunities as anti-cancer agents. Heal Sci J. 2018, 12, 1-25, https://dx.doi.org/10.21767/1791-809X.1000596.

8. D'Archivio, M.; Filesi, C.; Benedetto, R.; Gargiulo, R.; Giovannini, C.; Masella, R. Polyphenols, dietary sources and bioavailability. Annali dell'Istituto superiore di sanità 2007, 43, 348-361.

9. Naseer, S.; Hussain, S.; Naeem, N.; Pervaiz, M.; Rahman, M. The phytochemistry and medicinal value of Psidium guajava (guava). Clinical Phytoscience 2018, 4, 1-8, https://doi.org/10.1186/s40816-018-0093-8.

10. Dai, J.; Mumper, R.J. Plant Phenolics: Extraction, Analysis and Their Antioxidant and Anticancer Properties. Molecules 2010, 15, 7313-52, https://doi.org/10.3390/molecules15107313.

11. Seo, J.; Lee, S.; Elam, M.L.; Johnson, S.A.; Kang, J.; Arjmandi, B.H. Study to find the best extraction solvent for use with guava leaves (Psidium guajava L.) for high antioxidant efficacy. Food Science \& Nutrition 2014, 2, 174-180, https://doi.org/10.1002/fsn3.91.

12. Nicole, C. Role of Flavonoids in Oxidative Stress. Current Topics in Medicinal Chemistry 2001, 1, 569-590, https://doi.org/10.2174/1568026013394750.

13. Zhao, Y.; Sun, Z. Effects of gelatin-polyphenol and gelatin-genipin crosslinking on the structure of gelatin hydrogels. International Journal of Food Properties 2017, 20, S2822-S2832, https://doi.org/10.1080/10942912.2017.1381111.

14. Ghorpade, V.S. Preparation of hydrogels based on natural polymers via chemical reaction and crosslinking. Hydrogels Based Nat Polym. 2020, 91-118, https://doi.org/10.1016/B978-0-12-816421-1.00004-5.

15. Choi, I.; Lee, S.E.; Chang, Y.; Lacroix, M.; Han, J. Effect of oxidized phenolic compounds on crosslinking and properties of biodegradable active packaging film composed of turmeric and gelatin. LWT 2018, 93, 427-433, https://doi.org/10.1016/j.lwt.2018.03.065.

16. Alves, T.; Souza, J.F.; Amaral, V.A.; Rios, A.C.; Costa, T.; Crescencio, K.; Batain, F.; Grotto, D.; Lima, R.; Filho, L.S.; Junior, J.O.; Severino, P.; Aranha, N.; Chaud, M. Dense lamellar scaffold, biomimetically inspired, for reverse cardiac remodeling: Effect of proanthocyanidins and glutaraldehyde. Journal of Dispersion Science and Technology 2019, 1-14, https://doi.org/10.1080/01932691.2019.1678482.

17. Jimtaisong, A.; Saewan, N. Plant-Derived Polyphenols as Potential Crosslinking Agents for Methylcellulose-Chitosan Biocomposites. Solid State Phenomena 2018, 283, 140-146, https://doi.org/10.4028/www.scientific.net/SSP.283.140.

18. Ozdal, T.; Capanoglu, E.; Altay, F. A review on protein-phenolic interactions and associated changes. Food Research International 2013, 51, 954-970, https://doi.org/10.1016/j.foodres.2013.02.009.

19. Li, J.; Wu, C.; Li, F.; Yu, R.; Wu, X.; Shen, L.; Liu, Y.; Zeng, W. Optimization of ultrasound-assisted water 
extraction of flavonoids from Psidium guajava leaves by response surface analysis. Preparative Biochemistry \& Biotechnology 2019, 49, 21-29, https://doi.org/10.1080/10826068.2018.1466158.

20. Zhang, Y.; Abatzoglou, N. Review: Fundamentals, applications and potentials of ultrasound-assisted drying. Çam, M.; İçyer, N.C. Phenolics of pomegranate peels: extraction optimization by central composite design and alpha glucosidase inhibition potentials. Journal of Food Science and Technology 2015, 52, 1489-1497, https://doi.org/10.1007/s13197-013-1148-y.

21. de Souza, J.F.; Amaral, V.A.A.; Alves, T.F.R.; Batain, F.; de Moura Crescencio, K.M.; de Barros, C.T.; Rios, A.C.; Chaud, M.V.J.B.J.o.D. Polyphenols isolated from pomegranate juice (Punica granatum L.): Evaluation of physical-chemical properties by FTIR and quantification of total polyphenols and anthocyanins contente. 2020, 6, 45355-45372, https://doi.org/10.34117/bjdv6n7-234.

22. Kedare, S.B.; Singh, R.P. Genesis and development of DPPH method of antioxidant assay. Journal of Food Science and Technology 2011, 48, 412-422, https://doi.org/10.1007/s13197-011-0251-1.

23. Chefetz, B.; Hatcher, P.G.; Hadar, Y.; Chen, Y. Chemical and Biological Characterization of Organic Matter during Composting of Municipal Solid Waste. Journal of Environmental Quality 1996, 25, 776-785, https://doi.org/10.2134/jeq1996.00472425002500040018x.

24. Dick, D.P.; Knicker, H.; Âvila, L.G.; Inda, A.V.; Giasson, E.; Bissani, C.A. Organic matter in constructed soils from a coal mining area in southern Brazil. Organic Geochemistry 2006, 37, 1537-1545, https://doi.org/10.1016/j.orggeochem.2006.06.017.

25. Coutinho, H. Composição fenólica e avaliação da atividade antioxidante e citoprotetora dos extratos de Psidium guajava L. var. pyrifera e Psidium guajava L. var. pomífera. Cadernos de Cultura e Ciência 2014, 13, 8-15, https://doi.org/10.14295/cad.cult.cienc.v13i1.687.

26. Morais-Braga, M.F.B.; Carneiro, J.N.P.; Machado, A.J.T.; Sales, D.L.; dos Santos, A.T.L.; Boligon, A.A.; Athayde, M.L.; Menezes, I.R.A.; Souza, D.S.L.; Costa, J.G.M.; Coutinho, H.D.M. Phenolic composition and medicinal usage of Psidium guajava Linn.: Antifungal activity or inhibition of virulence? Saudi Journal of Biological Sciences 2017, 24, 302-313, https://doi.org/10.1016/j.sjbs.2015.09.028.

27. Kamboj, A.; Gupta, R.; Rana, A.; Kaur, R. Application and analysis of the Folin Ciocalteu method for the determination of the total phenolic content from extracts of Terminalia Bellerica. Eur J Biomed Pharm Sci. 2015, 2, 201-15.

28. De Alencar Filho, J.; MT, E.; Teixeira, H.A.; De Carvalho, I.S.; Milenna, V.D.O.; De Souza, N.; AC, A.; Tarc; Isio, C.D.L.; Pereira, E.C.; Amariz, I.A.; Sampaio, P.A.; Rolim-Neto, P.J.J.A.J.O.B. Development and validation of an analytical method for quantification of total flavonoids in Alternanthera brasiliana by $\begin{array}{lllll}\text { ultraviolet-visible } & \text { absorption } & \text { spectrophotometry. } & \mathbf{2 0 1 9}, & \text { 920-927, }\end{array}$ https://doi.org/10.5897/AJB2019.16905.

29. Singleton, V.L.; Orthofer, R.; Lamuela-Raventós, R.M. Analysis of total phenols and other oxidation substrates and antioxidants by means of Folin-Ciocalteu reagent. Methods Enzymol. 1999, 299, 152-78, https://doi.org/10.1016/S0076-6879(99)99017-1.

30. Zardo, I.; de Espíndola Sobczyk, A.; Marczak, L.D.F.; Sarkis, J. Optimization of Ultrasound Assisted Extraction of Phenolic Compounds from Sunflower Seed Cake Using Response Surface Methodology. Waste and Biomass Valorization 2019, 10, 33-44, https://doi.org/10.1007/s12649-017-0038-3.

31. Semerci, A.; Tunç, K.; Okur, İ. Antioxidant activity of the fruits of Pyracantha coccinea using ethanolic extract method. Food and Health 2020, 6, 35-40, https://doi.org/10.3153/FH20005.

32. Roslan, A.S.; Ando, Y.; Azlan, A.; Ismail, A.J.P.J.o.T.A.S. Effect of Glucose and Ascorbic Acid on Total Phenolic Content Estimation of Green Tea and Commercial Fruit Juices by Using Folin Ciocalteu and Fast Blue BB Assays. 2019, 42. 545-56.

33. Hudz, N.; Yezerska, O.; Shanaida, M.; Horcinova Sedlackova, V.; Wieczorek, P. Application of the FolinCiocalteu method to the evaluation of Salvia sclarea extracts. Pharmacia 2019, 66, 209-215, https://dx.doi.org/10.3897/pharmacia.66.e38976.

34. Coelho, K.D.; Paim, C.S.; Deuschle, R.A.N.; Bortolotto, J.W.; Deuschle, V.C.K.N. Desenvolvimento e avaliação da estabilidade e capacidade antioxidante de uma formulação em gel contendo o extrato das folhas de goiabeira (Psidium guajava L.). Rev Biomotriz. 2016, 10, 136-55.

35. Chen, Y.; Yao, F.; Ming, K.; Wang, D.; Hu, Y.; Liu, J. Polysaccharides from Traditional Chinese Medicines: Extraction, Purification, Modification, and Biological Activity. Molecules 2016, 21, 1-23, https://doi.org/10.3390/molecules21121705.

36. Tuan, P.M.; Anh, H.T.V.; Cam, L.T.H.; Chi, V.N.Q.; Oanh, D.T.B.; Khue, D.B. Extraction and encapsulation of polyphenols from guava leaves. Ann Food Sci Technol - AFST. 2016, 17, 34-40.

37. Kapoor, S.; Gandhi, N.; Tyagi, S.K.; Kaur, A.; Mahajan, B.V.C. Extraction and characterization of guava seed oil: A novel industrial byproduct. LWT 2020, 132, https://doi.org/10.1016/j.lwt.2020.109882.

38. Ahmad, M.; Mohammad, N.; Al-Maswood, A.; Aziz, M.A.; Alam, A.; Hossain; Islam, R.; Uddin, M. Comparison of antioxidant role of methanol, acetone and water extracts of Andrographis paniculata Nees. Journal of medicinal plant research 2020, 14, 428-437, https://doi.org/10.5897/JMPR2020.6999.

39. Silva, M.L.C.; Costa, R.S.; Santana, dos A.S.; Koblitk, M.G.B. Compostos fenólicos, carotenóides e atividade antioxidante em produtos vegetais. Semin Ciência Agrária 2010, 31, 669-82.

40. Silverstein, R.W.; Bassler, G.C. Spectrometric Identification of Organic Compounds. J Chem Educ. 1962, 
39, 546-53.

41. Zhao, X.; Zhu, H.; Zhang, G.; Tang, W. Effect of superfine grinding on the physicochemical properties and antioxidant activity of red grape pomace powders. Powder Technology 2015, 286, 838-844, https://doi.org/10.1016/j.powtec.2015.09.025.

42. Cascant, M.M.; Sisouane, M.; Tahiri, S.; Krati, M.E.; Cervera, M.L.; Garrigues, S.; de la Guardia, M. Determination of total phenolic compounds in compost by infrared spectroscopy. Talanta 2016, 153, 360365, https://doi.org/10.1016/j.talanta.2016.03.020.

43. Wang, L.; Wu, Y.; Xie, J.; Wu, S.; Wu, Z. Characterization, antioxidant and antimicrobial activities of green synthesized silver nanoparticles from Psidium guajava L. leaf aqueous extracts. Materials Science and Engineering: C 2018, 86, 1-8, https://doi.org/10.1016/j.msec.2018.01.003.

44. Medeiros, J.D.; Kanis, L.A. Avaliação do efeito de polietilenoglicóis no perfil de extratos de Mikania glomerata Spreng., Asteraceae, e Passiflora edulis Sims, Passifloraceae \%J Revista Brasileira de Farmacognosia. 2010, 20, 796-802 http://dx.doi.org/10.1590/S0102-695X2010005000001.

45. Permanyer, A.; Rebufa, C.; Kister, J. Reservoir compartmentalization assessment by using FTIR spectroscopy. Journal of Petroleum Science and Engineering 2007, 58, 464-471, https://doi.org/10.1016/j.petrol.2005.09.009. 